\title{
Zero Liquid Discharge of Ultrahigh-Salinity Brines with Temperature Swing Solvent Extraction
}

\author{
Chanhee Boo, Ian H. Billinge, Xi Chen, Kinnari M. Shah, and Ngai Yin Yip* \\ Cite This: Environ. Sci. Technol. 2020, 54, 9124-9131 \\ Read Online
}

ABSTRACT: Zero liquid discharge (ZLD) of hypersaline brines is technically and energetically challenging. This study demonstrates ZLD of ultrahigh-salinity brines using temperature swing solvent extraction (TSSE), a membrane-less and nonevaporative desalination technology. TSSE utilizes a low-polarity solvent to extract water from brine and then releases the water as a product with the application of low-temperature heat. Complete extraction of water from a hypersaline feed, simulated by $5.0 \mathrm{M} \mathrm{NaCl}$ solution ( $\approx 292 \mathrm{~g} / \mathrm{L}$ TDS), was achieved using diisopropylamine solvent. Practically all of the salt is precipitated as mineral solid waste and the product water contains $<5 \%$ of $\mathrm{NaCl}$ relative to the hypersaline feed brine. Consistent ZLD performance of high salt removals and product water quality was maintained in three repeated semibatch TSSE cycles, highlighting recyclability of the solvent. The practical applicability of the technique for actual field

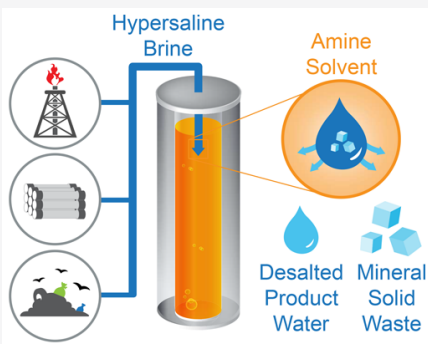
samples was demonstrated by ZLD of an irrigation drainage water concentrate. This study establishes the potential of TSSE as a more sustainable alternative to current thermal evaporation methods for zero liquid discharge of ultrahigh-salinity brines.

\section{INTRODUCTION}

High-salinity brines are generated from a variety of industrial sources, including flowback and produced water from oil and gas extraction, ${ }^{1-3}$ waste effluents from thermoelectric power plants, ${ }^{4,5}$ and discharges of coal-to-chemicals facilities. ${ }^{6,7}$ Other prominent examples are concentrates from inland brackish water desalination and landfill leachate treatment. ${ }^{8-11}$ Current management strategies for high-salinity waste streams are unsustainable. For example, the common disposal practices of direct discharge into surface water or sewer and deep well injection not only threaten to contaminate the environment and drinking water resources but can also be costly. ${ }^{9,12,13}$ The absence of cost-effective and environmentally benign brine management options can impede the associated economic activity. For instance, water production is curtailed when costintensive concentrate management approaches impose a prohibitively large financial burden on inland desalination operations that ultimately render the utilization of brackish groundwater infeasible. ${ }^{14}$ Similarly, the capacity for underground injection, the prevailing practice for flowback and produced water disposal, is rapidly approaching depletion, and the lack of viable alternatives can jeopardize oil and gas production. ${ }^{2,15}$ As such, there is a critical need for more environmentally sustainable approaches for the treatment of hypersaline waste streams.

Wastewater management strategies that eliminate liquid waste exiting the facility are termed zero liquid discharge (ZLD), ${ }^{16,17}$ often with the water recovered for reuse. Entirely abating liquid discharge lessens environmental impacts and diminishes pollution risks. The waste solids produced in ZLD can be more easily disposed in leach-proofed landfills or further processed to recover mineral byproducts of value. ${ }^{16}$
Where water recovery is applied, a nontraditional supply is generated for fit-for-purpose and even potable use. ${ }^{18,19}$ Increasingly stricter disposal regulations and financial incentives are motivating the development of ZLD technologies for waste brines. ${ }^{20,21}$ For example, all newly constructed coalto-chemical facilities in China must comply with ZLD rules for waste streams, to conserve local water resources and ecosystems. ${ }^{6}$ Stringent disposal regulations enforced by the Egyptian government to protect their primary water resource, the River Nile, drove implementation of the country's first ZLD-integrated chemical manufacturing facility. ${ }^{22}$

Conventional ZLD systems typically comprise a thermal brine concentrator to dewater the saline feedwater by evaporation to near saturation and a thermal crystallizer to vaporize more water and further concentrate the feed past saturation, precipitating mineral salts and other dissolved solids and contaminants (solar evaporation pond is another option but the method is land and capital intensive and often constrained by climate and hydrogeology). Eventually, almost all of the water is removed to leave only a slurry of solids as waste. ${ }^{23,24}$ However, the thermally driven brine concentrator and crystallizer are evaporative phase change processes with inherently very high energy intensities due to the exceedingly large vaporization enthalpy of water $(\approx 652-682 \mathrm{kWh} /$

Received: April 22, 2020

Revised: May 25, 2020

Accepted: June 19, 2020

Published: June 23, 2020 
$\left.\mathrm{m}^{3}\right){ }^{25-29}$ Additionally, these methods require high-grade thermal energy, i.e., steam that is $>100{ }^{\circ} \mathrm{C}$, and often also high-quality electrical energy for mechanical vapor compression. The development of innovative technologies that are more energy efficient will provide further impetus for the broader application of ZLD for sustainable management of hypersaline brines.

Temperature swing solvent extraction (TSSE) is a membrane-less and nonevaporative desalination technology that utilizes low-grade heat and a low-polarity solvent with temperature-dependent water solubility for the selective extraction of water over salt from saline feeds. ${ }^{30-34}$ Our recent study demonstrated the unique capability of TSSE for the desalination of hypersaline brines with a total dissolved solids (TDS) range of $\approx 58-234 \mathrm{~g} / \mathrm{L}$, using a swing between moderate temperatures of 15 and $68{ }^{\circ} \mathrm{C} .{ }^{30}$ TSSE desalination is not restricted by feedwater salinity, unlike membrane-based reverse osmosis (RO) with hydraulic pressure (or, equivalently, osmotic pressure) limitation. ${ }^{20,35,36}$ Because TSSE desalination does not require a phase change of water, the high energetic penalty of the vaporization enthalpy is inventively sidestepped and significantly higher energy efficiencies are attainable, specifically for hypersaline brines.

In this study, we extend the application of temperature swing solvent extraction and demonstrate the potential of the technology to achieve zero liquid discharge of ultrahighsalinity brines. The performance of diisopropylamine solvent in TSSE-ZLD for water extraction and salt precipitation was evaluated. To examine the recyclability of the ZLD process, salt removal, water recovery, and product water quality were further assessed in repeated semibatch TSSE experiments. TSSE-ZLD was then applied to treat an actual field sample of hypersaline irrigation drainage water concentrate. Finally, the implications of TSSE as a more sustainable alternative to achieve ZLD of hypersaline brines are discussed.

\section{TEMPERATURE SWING SOLVENT EXTRACTION FOR ZERO LIQUID DISCHARGE}

Working Principles of TSSE-ZLD. The working principles of TSSE-ZLD are illustrated in Figure 1. TSSE-ZLD utilizes a low-polarity solvent with temperature-dependent water solubility to extract water from hypersaline feeds. First, the ultrahigh-salinity feedwater is mixed into the solvent at temperature $T_{\mathrm{L}}$ (step I). The solvent possesses hydrophilic moieties in a mainly hydrophobic chemical structure and, thus, water favorably partitions from the aqueous brine phase into the solvent, while ionic species, such as $\mathrm{Na}^{+}$and $\mathrm{Cl}^{-}$, are retained in the brine. As the aqueous brine phase is being dewatered, salt concentrations increase and mineral solids eventually precipitate out when the solubility limit is exceeded. By using sufficient amounts of solvent relative to the brine volume, all of the water can be extracted to yield only solid precipitates and a single liquid phase of the solvent, i.e., no aqueous phase. The salt precipitates are sieved off, leaving a water-laden solvent (step II). The solvent is warmed to a moderately high temperature of $T_{\mathrm{H}}$ (below $\approx 80{ }^{\circ} \mathrm{C}$ ). Because the solubility of water in the solvent decreases with an increase in temperature, the temperature swing from $T_{\mathrm{L}}$ to $T_{\mathrm{H}}$ drives the phase separation of desalted water from the solvent, producing a biphasic mixture (step III). The aqueous phase of desalinated product water is easily decanted from the solvent phase. The regenerated solvent is cycled back for reuse in a

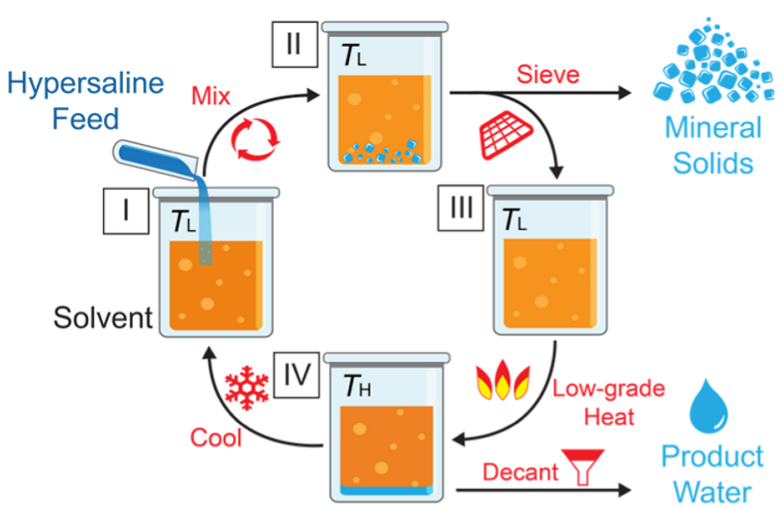

Figure 1. Schematic illustrating the working principles of temperature swing solvent extraction for zero liquid discharge of highly concentrated brines. A low-polarity solvent with temperaturedependent water solubility extracts all of the water from the hypersaline feed to induce salt precipitation. The solid precipitates are sieved off, leaving a water-laden solvent. A moderate temperature swing supplied by low-grade heat decreases the water solubility of the solvent, thus driving phase separation to yield desalinated product water.

subsequent TSSE-ZLD cycle after returning to temperature $T_{\mathrm{L}}$ (step IV).

\section{MATERIALS AND METHODS}

Materials and Chemicals. Diisopropylamine (DIPA, $\geq 99.5 \%$ ) from Sigma-Aldrich (St. Louis, MO) was used as received. Hypersaline brines were prepared by dissolving sodium chloride (ACS reagent grade $\mathrm{NaCl}, \mathrm{J}$. T. Baker, Phillipsburg, NJ) in deionized (DI) water obtained from a Milli-Q ultrapure water purification system (Millipore, Billerica, MA). Oil red O (Sigma-Aldrich) was dissolved in DIPA to yield $1.2 \mathrm{w} / \mathrm{w} \%$ solutions. To enhance the visual differentiation of the layers and facilitate decantation during TSSE-ZLD experiments, a few drops of the oil red $\mathrm{O}$ solution were dosed to the DIPA solvent. Poly(tetrafluoroethylene) membrane with a nominal pore size of $0.02 \mu \mathrm{m}$, PTF002LHOP, used to filter salt precipitates was obtained from Pall Corporation (Westborough, MA).

TSSE-ZLD Experiments. DIPA was used as the solvent for TSSE-ZLD of ultrahigh-salinity brines, simulated by $5.0 \mathrm{M}$ $\mathrm{NaCl}$ (292 g/L TDS). First, different feed brine volumes were introduced to DIPA at $5{ }^{\circ} \mathrm{C}$ in capped glass vials to achieve brine to solvent ratios, $\phi$, from 2.5 to $25.3 \mathrm{~mL} / \mathrm{mol}$. The combined brine and solvent were thoroughly mixed using a vortex mixer at $2000 \mathrm{rpm}$ for about $10 \mathrm{~s}$ and equilibrated in a cold bath at $T_{\mathrm{L}}=5^{\circ} \mathrm{C}$ for $1 \mathrm{~h}$. Salts precipitated on the bottom and wall of the glass vials were detached from the surfaces using bath sonication. Next, the samples were sieved through a microporous membrane by vacuum filtration. The filtered solids were dried and then weighed to evaluate salt removal. After filtration, the water-laden solvent was equilibrated in a warm bath at $T_{\mathrm{H}}=70{ }^{\circ} \mathrm{C}$ for $1 \mathrm{~h}$ to drive phase separation, yielding a biphasic mixture of solvent on top of desalted product water. The solvents after equilibration at $T_{\mathrm{L}}$ and $T_{\mathrm{H}}$ and the product water were carefully sampled using glass pipettes and the composition was further analyzed.

Characterization of Solvent Composition. Water content in the solvent was evaluated by a volumetric method using a Karl Fischer titrator (870 KF Titrino plus, Metrohm, Herisau, Switzerland). To analyze the salt $(\mathrm{NaCl})$ content, a 
known weight of the sample was first evaporated to remove all water and solvent. The salt residue was then redissolved in a known volume of DI water and measured using a calibrated conductivity meter (Orion Star A121, ThermoFisher Scientific, Waltham, MA). The salt content was determined by the weight percent of $\mathrm{NaCl}$ in the water-laden solvent.

Analysis of Product Water Quality. Salt $(\mathrm{NaCl})$ concentration in the product water was analyzed by first evaporating the samples to remove all water and solvent. The salt residue was then redissolved in a known volume of DI water and measured using a calibrated conductivity meter. Total organic carbon (TOC) in the product water was evaluated using a TOC analyzer (QbD1200, Hach, Loveland, $\mathrm{CO})$ to determine the solvent concentration.

TSSE-ZLD Experiments With Actual Brine Feed. Field samples of actual reverse osmosis concentrate were obtained from the San Luis plant, CA, which desalinates irrigation drainage water from the San Joaquin Valley. The RO effluent was thermally evaporated until the volume was reduced by $\approx$ 8 -fold. Mineral solids that precipitated out during evaporation were removed from the solution by vacuum filtration through a $0.45 \mu \mathrm{m}$ cellulose acetate filter (Corning $0.45 \mu \mathrm{m}, \mathrm{NY}$ ). Saturated $\mathrm{NaCl}$ solution $(\approx 5.5 \mathrm{M} \mathrm{NaCl})$ was added until the electrical conductivity of the filtered brine reached $242.7 \mathrm{mS} /$ $\mathrm{cm}$ (i.e., equivalent to a $5.0 \mathrm{M} \mathrm{NaCl}$ solution). $\mathrm{pH}$, conductivity, and TOC concentration of the field sample and prepared brine solution were evaluated and total dissolved solids (TDS) concentration was measured following ASTM D5907. ${ }^{37}$ The solution properties are summarized in Table S1 of the Supporting Information. TSSE-ZLD experiments were performed by introducing $1.5 \mathrm{~mL}$ of the prepared brine feed into $60 \mathrm{~g}$ of DIPA solvent with a brine to solvent ratio, $\phi$, of $2.5 \mathrm{~mL} / \mathrm{mol}$ and employing temperature swing from $T_{\mathrm{L}}=5{ }^{\circ} \mathrm{C}$ to $T_{\mathrm{H}}=70{ }^{\circ} \mathrm{C}$.

\section{RESULTS AND DISCUSSION}

TSSE Achieves Zero Liquid Discharge of UltrahighSalinity Brines. Increasing amounts of $5.0 \mathrm{M} \mathrm{NaCl}$ brine were introduced into DIPA solvent to evaluate TSSE-ZLD performance at brine to solvent ratios, $\phi$, of $2.5,5.1,10.1,15.2$, 20.2 , and $25.3 \mathrm{~mL} / \mathrm{mol}$. Water content, $c_{\mathrm{w}}$, is defined as the weight percent of water in the water-laden solvent. The water content in DIPA after equilibration at $T_{\mathrm{L}}=5{ }^{\circ} \mathrm{C}$ (blue circle symbols of Figure $2 \mathrm{~A}$ ) represents the water extracted from the aqueous brine solution, and it monotonically increases as $\phi$ is increased from 2.5 to $15.2 \mathrm{~mL} / \mathrm{mol}$, indicating that the solvent has yet to be fully saturated with water. As more brine was introduced to the solvent in excess of $\phi=15.2 \mathrm{~mL} / \mathrm{mol}, c_{\mathrm{w}}$ plateaued at $\approx 9.1 \mathrm{w} / \mathrm{w} \%$ and then slightly decreased to $8.5 \mathrm{w} /$ w\% at $\phi$ of $25.3 \mathrm{~mL} / \mathrm{mol}$. Therefore, with $5.0 \mathrm{M} \mathrm{NaCl}$ brine, the DIPA solvent is saturated with water at $\approx 9.1 \mathrm{w} / \mathrm{w} \%$, around a brine to solvent ratio of $15.2 \mathrm{~mL} / \mathrm{mol}$. The slight $c_{\mathrm{w}}$ decrease at the highest $\phi$ investigated is attributed to the reverse transport of water from the solvent to the highly concentrated salt solution, i.e., the chemical potential of water is lower for the aqueous brine phase than the solvent phase and, hence, previously extracted water partitions from the solvent to the brine. ${ }^{31}$

Images of the brine and DIPA mixtures at $T_{\mathrm{L}}$ provide further corroborative evidence of the solvent saturation results (Figure 3 , with a magnification of the vial bottom). For $\phi<15.2 \mathrm{~mL} /$ mol, two distinct phases comprising a single liquid layer of solvent (colored with red dye) and solid precipitates (white
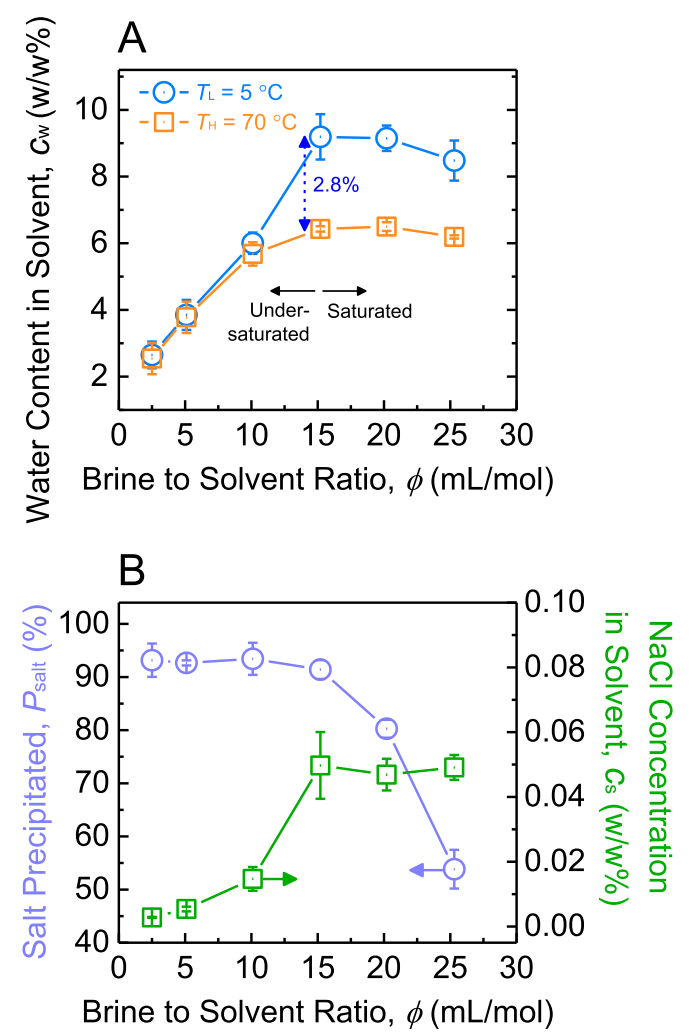

Figure 2. (A) Water content in solvent, $c_{\mathrm{w}}$, during TSSE-ZLD experiments at $T_{\mathrm{L}}=5{ }^{\circ} \mathrm{C}$ and $T_{\mathrm{H}}=70{ }^{\circ} \mathrm{C}$ with brine $(5.0 \mathrm{M} \mathrm{NaCl})$ to solvent (DIPA) ratios, $\phi$, of $2.5,5.1,10.1,15.2,20.2$, and $25.3 \mathrm{~mL} /$ mol. (B) Salt precipitated, $P_{\text {salt }}$ defined as percent $\mathrm{NaCl}$ removed in precipitates relative to initial $5.0 \mathrm{M} \mathrm{NaCl}$ brine (violet circle symbols, left vertical axis) and concentration of $\mathrm{NaCl}$ in the water-laden solvent, $c_{\mathrm{s}}$, after equilibration at $T_{\mathrm{L}}=5{ }^{\circ} \mathrm{C}$ (green square symbols, right vertical axis), as a function of $\phi$. Data points and error bars are means and standard deviations, respectively, from duplicate experiments.

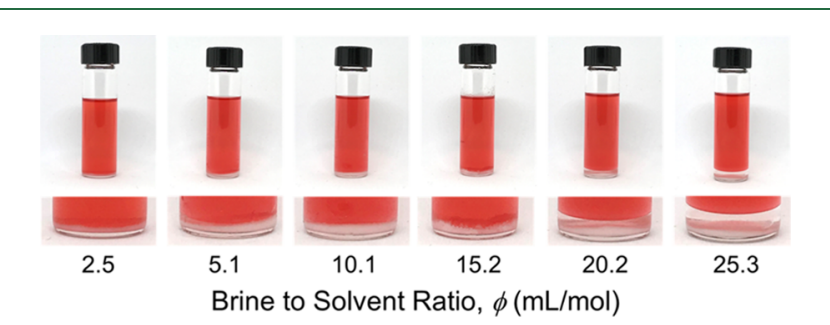

Figure 3. Photographic images of $5.0 \mathrm{M} \mathrm{NaCl}$ brine combined with DIPA solvent at brine volume to solvent mole ratios, $\phi$, of $2.5,5.1$, $10.1,15.2,20.2$, and $25.3 \mathrm{~mL} / \mathrm{mol}$. For better visualization of the two phases (i.e., solvent and aqueous layers), oil red $\mathrm{O}$ dye was dosed to stain the solvent. Only two phases (solvent and solid) were observed for $\phi$ of $2.5-15.2 \mathrm{~mL} / \mathrm{mol}$, whereas an additional aqueous phase was noticed for $\phi$ of 20.2 and $25.3 \mathrm{~mL} / \mathrm{mol}$.

solids at the bottom of the vial) were observed. This observation agrees with the complete deprivation of water from the aqueous brine added. In contrast, once the solvent is saturated with water at $\phi>15.2 \mathrm{~mL} / \mathrm{mol}$, water in the $\mathrm{NaCl}$ solution is unable to further partition into the solvent and, thus, an additional aqueous brine phase is seen (clear solution below solvent).

The water-laden solvents were brought to $T_{\mathrm{H}}=70{ }^{\circ} \mathrm{C}$ (step III of Figure 1), lowering the solubility limit of water in solvent, and $c_{\mathrm{w}}$ was evaluated (orange square symbols of Figure 
2A). The solvent exhibited almost equivalent water contents at $T_{\mathrm{H}}$ and $T_{\mathrm{L}}$ for $\phi$ of $2.5-10.1 \mathrm{~mL} / \mathrm{mol}$. This is because the amount of water extracted by the solvent at $T_{\mathrm{L}}$ was limited by the relatively small volume of aqueous brine added. Hence, $c_{\mathrm{w}}$ did not exceed the water solubility limit at $T_{\mathrm{H}}$, even though the solubility limit was lowered at the elevated temperature, i.e., water did not phase separate out from the solvent at $T_{\mathrm{H}}$. Conversely, when water solubility limit at the elevated temperature drops below the water content at $T_{\mathrm{L}}$, water partitions out from the solvent phase and $c_{\mathrm{w}}$ is lower at $T_{\mathrm{H}}$ relative to $T_{\mathrm{L}}$, as is observed for $\phi \geq 15.2 \mathrm{~mL} / \mathrm{mol}$. The difference between water contents in the solvent at $T_{\mathrm{L}}$ and $T_{\mathrm{H}}$ represents the water production in a TSSE-ZLD cycle. The greatest $c_{\mathrm{w}}$ difference of $\approx 2.8 \mathrm{w} / \mathrm{w} \%$ was achieved at $\phi \approx 15.2$ $\mathrm{mL} / \mathrm{mol}$. That is, water production is maximized when the solvent is, first, fully saturated at $T_{\mathrm{L}}\left(c_{\mathrm{w}} \approx 9.2 \mathrm{w} / \mathrm{w} \%\right)$ and the water solubility limit is then depressed by swinging the temperature to $T_{\mathrm{H}}\left(c_{\mathrm{w}} \approx 6.4 \mathrm{w} / \mathrm{w} \%\right)$, to yield $\approx 2.8 \mathrm{w} / \mathrm{w} \%$ of desalted product water (relative to the weight of the saturated solvent) from the hypersaline brine feed.

Dissolved $\mathrm{NaCl}$ in Feed Precipitates Out as Mineral Solids. Salt precipitated, $P_{\text {salt }}$ is defined as the percent of $\mathrm{NaCl}$ removed as solid precipitates relative to the hypersaline feedwater, i.e., $P_{\text {salt }}=W_{\mathrm{p}} / W_{\mathrm{f}}$, where $W_{\mathrm{p}}$ and $W_{\mathrm{f}}$ denote the weight of salt in precipitates and initial feed, respectively. We note that because of the inevitable loss of very small salt precipitates $(<\approx 20 \mathrm{~nm}$, which is the membrane pore size) during vacuum filtration, the experimentally measured $W_{\mathrm{p}}$ is, hence, less than the actual amount of $\mathrm{NaCl}$ solids formed in TSSE-ZLD. As the violet circle symbols of Figure 2B show (left vertical axis), high $P_{\text {salt }}>90 \%$ were measured with relatively small brine volumes being added to the solvent $(\phi$ from 2.5 to $15.2 \mathrm{~mL} / \mathrm{mol}$ ), corresponding to the complete extraction of water from the hypersaline feed and induced precipitation of most of the salt in the $5.0 \mathrm{M} \mathrm{NaCl}$ brine. Salt that did not precipitate out partitioned into the solvent phase at $T_{\mathrm{L}}$ (green square symbols, the right vertical axis of Figure 2B) and eventually ended up in the phase-separated product water at $T_{\mathrm{H}}$. In contrast, an abrupt drop in $P_{\text {salt }}$ was noted for $\phi$ $>15.2 \mathrm{~mL} / \mathrm{mol}$, which coincides with the solvent being fully saturated with water (peaking of $c_{\mathrm{w}}$ ). As described earlier, once the solvent is fully saturated, the further dosing of brine forms an additional aqueous phase of $\mathrm{NaCl}$ solution (Figure 3). A substantial amount of salt, thus, remains dissolved in the aqueous phase, resulting in a significant decline in the percentage of salt precipitated for $\phi>15.2 \mathrm{~mL} / \mathrm{mol}$.

The weight percent concentration of $\mathrm{NaCl}$ in the waterladen solvent phase at $T_{\mathrm{L}}=5{ }^{\circ} \mathrm{C}, c_{\mathrm{s}}$, increased as more brine was added (green square symbols, the right vertical axis of Figure $2 \mathrm{~B}$ ), up to $\phi=15.2 \mathrm{~mL} / \mathrm{mol}$ (i.e., solvent is not yet fully saturated with water). In contrast, after the solvent is fully saturated with water, salt does not further partition into the solvent, ${ }^{31,32}$ as evident by the comparable $c_{\mathrm{s}}$ for $\phi \geq 15.2 \mathrm{~mL} /$ mol. The concentration of $\mathrm{NaCl}$ in the solvent for different amounts of brine addition follows the same trend as the water content in the solvent, $c_{\mathrm{w}}$ (blue circle symbols of Figure $2 \mathrm{~A}$ ): a monotonic increase up to the point of saturation $(\phi \approx 15.2$ $\mathrm{mL} / \mathrm{mol}$ ), then leveling off. This similar behavior suggests that the partitioning of water and salt into the solvent phase is related. Using the $c_{s}$ data of Figure 2B, the percentage of salt in the solvent phase at $T_{\mathrm{L}}$, relative to the initial $\mathrm{NaCl}$ in the $5.0 \mathrm{M}$ brine feed, can be calculated. For the entire range of $\phi$ investigated, the relative amount of salt in the solvent phase is
$<0.6 \%$. That is, for mixtures without an aqueous brine phase, i.e., $\phi<15.2 \mathrm{~mL} / \mathrm{mol}$, the sum of salt precipitate weight and $\mathrm{NaCl}$ in the solvent is still less than $100 \%$. This apparent deficit in $\mathrm{NaCl}$ mass balance is attributed to the filter size limitation mentioned earlier. Therefore, the actual percentages of $\mathrm{NaCl}$ precipitated as mineral solids are higher than the experimental $P_{\text {salt }}$ reported in Figure 2B and are only slightly below $100 \%$ for $\phi \leq 15.2 \mathrm{~mL} / \mathrm{mol}$.

ZLD Performance is Maintained in Repeated TSSE Cycles. TSSE-ZLD can be readily scaled up to a continuous process, as conceptualized in Figure 4. Hypersaline feedwater is

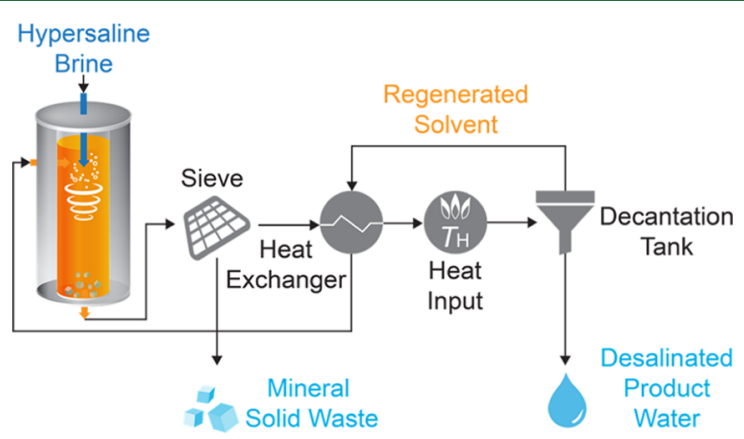

Figure 4. Process flow diagram of a conceptual continuous TSSEZLD operation.

introduced at the top of the liquid-liquid extraction column and contacts the solvent at temperature $T_{\mathrm{L}}$. The solvent progressively extracts water from the denser aqueous phase as it sinks toward the bottom, eventually removing all water from the hypersaline feed. The salts precipitate out and ultimately settle at the bottom of the column. The solid precipitates are carried out of the column by the exiting stream of watersaturated solvent and are sieved off. The solvent is then channeled to the heat exchanger. Heat transfers across the exchanger, from the warm regenerated solvent to the colder water-saturated solvent. The solvent is further heated to $T_{\mathrm{H}}$ by a relatively low-temperature thermal input (e.g., low-grade waste heat or solar thermal energy). The warmed stream is then sent to the decantation tank. Because the solubility of water in the solvent is lower at the elevated temperature, the previously extracted water demixes from the solvent. Aided by gravity, the denser aqueous phase forms a separate layer below the lighter solvent phase and is decanted off to yield desalted product water. After exchanging sensible heat with the incoming water-saturated solvent, the regenerated solvent with reduced water content is cycled back to the extraction column for reuse.

Continuous operation of TSSE-ZLD was simulated by semibatch experiments with repeated extraction cycles, using DIPA as the solvent and $5.0 \mathrm{M} \mathrm{NaCl}$ solution as the hypersaline feed. The results of single TSSE-ZLD cycles (Figure 2A) indicate that DIPA approaches saturation with 9.2 w/w\% water at $T_{\mathrm{L}}=5{ }^{\circ} \mathrm{C}$ and reaches the lowered solubility limit of $\approx 6.4 \mathrm{w} / \mathrm{w} \%$ at $T_{\mathrm{H}}=70{ }^{\circ} \mathrm{C}$, corresponding to water production of $\approx 2.8 \mathrm{w} / \mathrm{w} \%$ from $5.0 \mathrm{M} \mathrm{NaCl}$ brine. To simulate solvent regeneration in continuous TSSE-ZLD operation (Figure 4), the DIPA solvent was preloaded with DI water at $\approx 6.4 \mathrm{w} / \mathrm{w} \%$ and consecutively reused in three repeated TSSE cycles. Fresh brine $(5.0 \mathrm{M} \mathrm{NaCl}, 1.5 \mathrm{~mL})$ was introduced into $60 \mathrm{~g}$ of DIPA solvent in each extraction cycle to achieve a brine to solvent ratio, $\phi$, of $2.5 \mathrm{~mL} / \mathrm{mol}$. The 


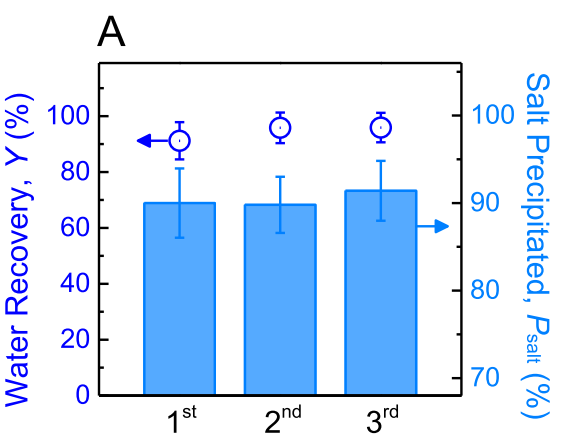

TSSE-ZLD Cycle

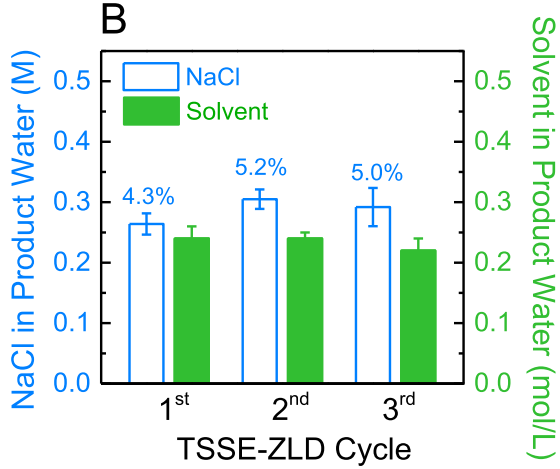

TSSE-ZLD Cycle

Figure 5. (A) Water recovery (symbols, the left vertical axis) and salt precipitated (columns, the right vertical axis) obtained from repeated TSSEZLD cycles with a feed of $5.0 \mathrm{M} \mathrm{NaCl}$ brine and DIPA as the solvent. (B) $\mathrm{NaCl}$ and residual solvent concentrations in the product water collected from each TSSE-ZLD cycle (blue empty columns, the left vertical axis and green filled columns, the right vertical axis, respectively). The column labels indicate the weight percent of $\mathrm{NaCl}$ in product water relative to an initial feed of $5.0 \mathrm{M} \mathrm{NaCl}$ brine. A brine to solvent ratio, $\phi$, of $2.5 \mathrm{~mL} /$ mol and a temperature swing from $T_{\mathrm{L}}=5{ }^{\circ} \mathrm{C}$ to $T_{\mathrm{H}}=70^{\circ} \mathrm{C}$ were employed for all TSSE-ZLD cycles. Data points and error bars are mean and standard deviation, respectively, from duplicate experiments.

selected $\phi$ value ensures complete extraction of water from the $5.0 \mathrm{NaCl}$ brine in continuous extraction cycles. The precipitated solids were sieved off with a microporous membrane under vacuum filtration and then weighed after drying. The product water collected from each extraction cycle was weighed to evaluate water recovery and analyzed for $\mathrm{NaCl}$ and solvent residue concentrations.

Water recovery, $Y$, and salt precipitated, $P_{\text {salt, }}$ of each extraction cycle were evaluated to examine recyclability of TSSE-ZLD. Water recovery is defined as the weight percent of the product water relative to the initial brine feed. High $Y$ of 91.2, 95.8, and 95.9\% was obtained for the 1st, 2nd, and 3rd cycles, respectively (symbols, the left vertical axis of Figure $5 \mathrm{~A})$. Measured water recoveries were marginally below $100 \%$, even though all of the water was extracted from the brine feed in each ZLD cycle. This discrepancy is mainly attributed to the conservative sampling of the product water during separation from the biphasic mixture to avoid contamination by the solvent and slight undersaturation of the solvent in the 1st cycle. Importantly, $Y$ remained practically constant when the solvent was reused for the 2 nd and 3 rd cycles, indicating that the ability of the solvent to extract water from the hypersaline feed is preserved. Almost all of the salt in the $5.0 \mathrm{M} \mathrm{NaCl}$ brines precipitated out after water was extracted by the solvent and high $P_{\text {salt }}$ of $\approx 91,90$, and $91 \%$ was maintained in the 1 st, 2nd, and 3rd extraction cycles, respectively (columns, the right vertical axis of Figure 5A). The consistent water recoveries and salt removals across multiple cycles underscore the potential for reproducible TSSE-ZLD performance when the same solvent is reused. At the end of the last cycle, the DIPA solvent was measured to hold $\approx 6.5 \mathrm{w} / \mathrm{w} \%$ water, effectively identical to the initial water content of $6.4 \mathrm{w} / \mathrm{w} \%$ (Figure S1 of the Supporting Information), and, thus, further highlights solvent recyclability in continuous TSSE-ZLD operation.

The product water quality of TSSE-ZLD in repeated extraction cycles was assessed for salt concentration and solvent residue content. $\mathrm{NaCl}$ concentrations in the product water from each extraction cycle were 0.26, 0.31, and 0.29 M (blue empty columns, the left vertical axis of Figure 5B). The product water salt concentrations are markedly lower than the hypersaline feed of $5.0 \mathrm{M} \mathrm{NaCl}$ brine (93.8-94.8\% reduction), and the amount of salt in the product water corresponds to 4.3, 5.2 , and $5.0 \mathrm{w} / \mathrm{w} \%$ relative to $\mathrm{NaCl}$ in the initial brine. We note that, because the solvent is reused for sequential cycles in the semibatch experiment, there may be some inadvertent contamination of the water-laden solvent by trace $\mathrm{NaCl}$ solid residues during the low-temperature step, possibly leading to slight over-reporting of the product water salt concentration. Solvent residues in the product water were comparable at $\approx 0.2$ $\mathrm{mol} / \mathrm{L}$ between the extraction cycles investigated (green filled columns, the right vertical axis of Figure $5 \mathrm{~B}$ ). The consistent salt concentrations and solvent residue contents in the product water provide additional support that ZLD performance is maintained in repeated TSSE cycles reusing the same solvent. Osmotic pressure reductions of 93.1-93.9\% were achieved, from 308.4 bar of the brine feed to $18.8-21.3$ bar of the product water (both residual $\mathrm{NaCl}$ and solvent contribute to osmotic pressure). With substantially lowered total dissolved solids (TDS) concentration and osmotic pressure, the desalted product water from TSSE-ZLD can be further polished using conventional techniques, such as reverse osmosis (RO), for post-treatment with much less energy demand and fewer technical constraints, to yield a fit-for-purpose reuse stream and even fresh drinking water. ${ }^{30}$ Crucially, the trace amount of solvent residues can also be recovered from the product water and returned to the TSSE-ZLD cycle to curtail solvent loss and yield an essentially solvent-free effluent output. ${ }^{30}$

TSSE Shows Promising Potential as an Alternative ZLD Approach. The potential of TSSE for ZLD is further evaluated with an actual field sample. Briefly, the hypersaline feed was prepared by the evaporative concentration of the RO effluent from the San Luis plant, CA, which desalinates irrigation drainage water from the San Joaquin Valley to reach TDS concentration of $\approx 295 \mathrm{~g} / \mathrm{L}$ (i.e., approximately equivalent to $5.0 \mathrm{M} \mathrm{NaCl}$ brine). The properties of the samples are summarized in Table $\mathrm{S} 1$ of the Supporting Information. The hypersaline feed was then introduced to the DIPA solvent in a TSSE-ZLD cycle, as illustrated in Figure 1. The extraction of all of the water from the brine sample precipitated $\approx 85.2 \%$ of the dissolved solids, which were removed by filtration (blue columns of Figure 6, the left vertical axis). Product water TDS concentration was substantially reduced by $-88.8 \%$ relative to the feed brine, from 295.4 to $33.1 \mathrm{~g} / \mathrm{L}$ (green columns of Figure 6, the right vertical axis). TOC concentration of the product water $(0.27$ $\mathrm{mol} / \mathrm{L}$ ) was comparable to those obtained from semibatch 


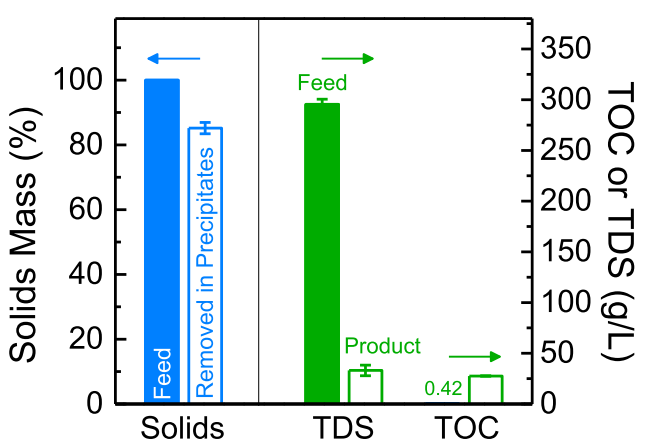

Figure 6. Percentage of solids mass removed in precipitates relative to the concentrated brine feed in TSSE-ZLD (blue filled and empty columns, the left vertical axis). Total dissolved solids (TDS) and total organic carbon (TOC) concentrations of the actual brine feed and product water from TSSE-ZLD experiments (green filled and empty columns, the right vertical axis). Data points and error bars are mean and standard deviation, respectively, from duplicate experiments.

TSSE-ZLD experiments with $5.0 \mathrm{M} \mathrm{NaCl}$ solution as brine feed (Figure 5B), which had no initial organic content, indicating that TOC in the product water is mostly attributable to the solvent that has partitioned to the aqueous phase.

To provide a first-order estimate of the energy requirement for TSSE-ZLD, a basic analysis was performed (the methodology is detailed in the Supporting Information, with Figure S2 showing the specific energy requirement as a function of $\phi$ ). The specific energy consumption of TSSE-ZLD of $5.0 \mathrm{M} \mathrm{NaCl}$ brine is estimated to be $172 \mathrm{kWh}_{\mathrm{th}} / \mathrm{m}^{3}$ of the treated feedwater, for a brine to solvent ratio, $\phi$, of $2.5 \mathrm{~mL} / \mathrm{mol}$ and heat exchanger efficiency of $90 \%$. The $\phi$ value of $2.5 \mathrm{~mL} / \mathrm{mol}$ represents extraction performance achievable with DIPA, i.e., complete extraction of water from the $5.0 \mathrm{M} \mathrm{NaCl}$ brine in repeated extraction cycles, as demonstrated in the previous semibatch experiments (Figure 5A,B), thus enabling continuous TSSE-ZLD operation. While the energy requirement appears high, it is considerably lower than the water vaporization enthalpy of $\approx 682 \mathrm{kWh}_{\mathrm{th}} / \mathrm{m}^{3}$ for the highly concentrated $\mathrm{NaCl}$ solution. ${ }^{27}$ In actual thermal brine concentrators and crystallizers, latent heat of the vaporized water can be utilized more than once with multiple stages of heat exchangers and vapor compression. Assuming a gained output ratio of 5 , the thermal energy input would be $\approx 136$ $\mathrm{kWh}_{\mathrm{th}} / \mathrm{m}^{3}$ (electrical energy is additionally needed for vapor compression). Therefore, the first-order approximation for the energy requirement of TSSE-ZLD is comparable to current thermal evaporation methods.

The theoretical minimum energy for zero liquid discharge of saline feeds, $E_{\min , \text { ZLD }}$, is equivalent to the Gibbs free energy of separation (presentation of the equations is found in the Supporting Information). For $5.0 \mathrm{M} \mathrm{NaCl}, E_{\min , \mathrm{ZLD}}$ is 14.9 $\mathrm{kWh} / \mathrm{m}^{3}$, i.e., the projected energy efficiency of TSSE-ZLD relative to $E_{\min , Z L D}$ is $8.7 \%$. However, the energy efficiency of thermally driven separations, regardless of technology, is bound by the Carnot limit, $1-T_{\mathrm{L}} / T_{\mathrm{H} \cdot}{ }^{28,29}$ For the low and high temperatures of 5 and $70{ }^{\circ} \mathrm{C}$, respectively, employed for this study, the Carnot efficiency is $18.9 \%$. Therefore, the energy efficiency of TSSE-ZLD is a propitious and practicable 0.46 of the Carnot limit. Additionally, we emphasize that the operating parameters (e.g., $T_{\mathrm{L}}$ and $T_{\mathrm{H}}$ ) were not optimized for the preliminary assessment and that the actual energy requirement for a practical TSSE-ZLD process would need to further incorporate auxiliary costs (e.g., pumps, posttreatment polishing, and cooling).

The specific energy requirement is inversely proportional to the operating $\phi$ (Figure S2): using a higher-performing solvent that is able to extract more water from the brine feed per unit solvent yields a reciprocal decrease in heat demand. Critically, the energy input for TSSE-ZLD can be affordably obtained from low-grade thermal sources because only a moderate temperature is required to drive the separation (heat supply used in this study is just $70{ }^{\circ} \mathrm{C}$ ), rather than more expensive high-grade steam $\left(>100{ }^{\circ} \mathrm{C}\right)$ needed for evaporative ZLD methods and also prime energy of electricity for mechanical vapor compression. ${ }^{38,39}$ Hence, more sustainable energy supplies such as industrial waste heat, shallow-well geothermal, and low-concentration solar collectors can be utilized for TSSE-ZLD. ${ }^{40,41}$

Temperature Swing Solvent Extraction Holds Promise as a Sustainable Alternative to Achieve Zero Liquid Discharge of Highly Concentrated Brines. This study demonstrates the potential of temperature swing solvent extraction for the unprecedented zero liquid discharge treatment of hypersaline brines with extremely high total dissolved solids concentrations of $\approx 292 \mathrm{~g} / \mathrm{L}$. Together with the findings of our previous work, where the technology was applied for the energy-efficient dewatering of high-salinity brines with up to $234 \mathrm{~g} / \mathrm{L}$ TDS, ${ }^{30}$ TSSE can be a more sustainable alternative approach for ZLD. Current ZLD systems employ a thermal concentrator to dewater the hypersaline feed, followed by a brine crystallizer to further concentrate the stream to supersaturation and precipitate mineral solids as waste. ${ }^{24}$ However, both thermal brine concentrator and crystallizer are based on the evaporative phase change of water and, hence, require high-grade steam heat. $^{24}$ Additionally, the approaches commonly integrate mechanical vapor compression, which consumes prime electrical energy and, thus, further increases the energy intensity. Replacing the evaporative methods with TSSE can achieve greater cost effectiveness for ZLD, as only moderate temperatures are needed (below $70{ }^{\circ} \mathrm{C}$ in this study) and, thus, the heat input can be supplied by inexpensive low-grade thermal sources. Additionally, the mild operating temperatures, together with only low pumping pressures required for fluid circulation, can potentially translate to a lower capital equipment cost for TSSE-ZLD. Discovery of better solvents and further performance advancements, e.g., higher water extraction yields and optimized operating temperatures, can realize TSSE as a competitive ZLD approach.

\section{ASSOCIATED CONTENT}

\section{Supporting Information}

The Supporting Information is available free of charge at https://pubs.acs.org/doi/10.1021/acs.est.0c02555.

Details on the assessment of energy consumption and calculation of theoretical minimum energy for ZLD; solution properties of the actual RO concentrate (Table $\mathrm{S} 1$ ); water content in the DIPA solvent (Figure S1); specific heat energy to treat hypersaline feed by TSSEZLD (Figure S2) (PDF) 


\section{AUTHOR INFORMATION}

\section{Corresponding Author}

Ngai Yin Yip - Department of Earth and Environmental Engineering and Columbia Water Center, Columbia University, New York, New York 10027-6623, United States; (1) orcid.org/0000-0002-1986-4189; Phone: +1 (212) 8542984; Email: n.y.yip@columbia.edu

\section{Authors}

Chanhee Boo - Department of Earth and Environmental Engineering, Columbia University, New York, New York 100276623, United States; 으이. orcid.org/0000-0003-4595-9963

Ian H. Billinge - Department of Earth and Environmental Engineering, Columbia University, New York, New York 100276623, United States

Xi Chen - Department of Earth and Environmental Engineering, Columbia University, New York, New York 10027-6623, United States

Kinnari M. Shah - Department of Earth and Environmental Engineering, Columbia University, New York, New York 100276623, United States

Complete contact information is available at:

https: / / pubs.acs.org/10.1021/acs.est.0c02555

\section{Notes}

The authors declare no competing financial interest.

\section{ACKNOWLEDGMENTS}

This material is based upon work supported by the United States Bureau of Reclamation, Grant R19AC00111.

\section{REFERENCES}

(1) Vidic, R. D.; Brantley, S. L.; Vandenbossche, J. M.; Yoxtheimer, D.; Abad, J. D. Impact of Shale Gas Development on Regional Water Quality. Science 2013, 340, No. 1235009.

(2) Shaffer, D. L.; Chavez, L. H. A.; Ben-Sasson, M.; Castrillon, S. R. V.; Yip, N. Y.; Elimelech, M. Desalination and Reuse of High-Salinity Shale Gas Produced Water: Drivers, Technologies, and Future Directions. Environ. Sci. Technol. 2013, 47, 9569-9583.

(3) Chang, H. Q.; Li, T.; Liu, B. C.; Vidic, R. D.; Elimelech, M.; Crittenden, J. C. Potential and implemented membrane-based technologies for the treatment and reuse of flowback and produced water from shale gas and oil plays: A review. Desalination 2019, 455, 34-57.

(4) Karanikola, V.; Boo, C.; Rolf, J.; Elimelech, M. Engineered Slippery Surface to Mitigate Gypsum Scaling in Membrane Distillation for Treatment of Hypersaline Industrial Wastewaters. Environ. Sci. Technol. 2018, 52, 14362-14370.

(5) Yu, X. G.; Yang, H.; Lei, H.; Shapiro, A. Experimental evaluation on concentrating cooling tower blowdown water by direct contact membrane distillation. Desalination 2013, 323, 134-141.

(6) Xiong, R. H.; Wei, C. Current status and technology trends of zero liquid discharge at coal chemical industry in China. J. Water Process Eng. 2017, 19, 346-351.

(7) Pan, L. Y.; Liu, P.; Ma, L. W.; Li, Z. A supply chain based assessment of water issues in the coal industry in China. Energy Policy 2012, 48, 93-102.

(8) Pramanik, B. K.; Shu, L.; Jegatheesan, V. A review of the management and treatment of brine solutions. Environ. Sci.: Water Res. Technol. 2017, 3, 625-658.

(9) Jones, E.; Qadir, M.; van Vliet, M. T. H.; Smakhtin, V.; Kang, S. $\mathrm{M}$. The state of desalination and brine production: A global outlook. Sci. Total Environ. 2019, 657, 1343-1356.

(10) Schiffler, M. Perspectives and challenges for desalination in the 21st century. Desalination 2004, 165, 1-9.
(11) Aziz, H. A. Control and Treatment of Landfill Leachate for Sanitary Waste Disposal; Information Science Reference: Hershey, 2016; p xvi, 459 pages.

(12) Brady, P. V.; Kottenstette, R. J.; Mayer, T. M.; Hightower, M. M. Inland Desalination: Challenges and Research Needs. J. Contemp. Water Res. Educ. 2005, 132, 46-51.

(13) Estrada, J. M.; Bhamidimarri, R. A review of the issues and treatment options for wastewater from shale gas extraction by hydraulic fracturing. Fuel 2016, 182, 292-303.

(14) National Research Council (U.S.). Committee on Advancing Desalination Technology. In Desalination: A National Perspective; National Academies Press: Washington, DC, 2008; p xiv, 298 p.

(15) Turrell, J.; Herbert, L. M.; Lienhard, J. H.; McGehee, J. P.; Riley, T., Contemporary Arts Museum. James Turrell: Spirit and Light; Contemporary Arts Museum: Houston, 1998; p 71.

(16) Tong, T. Z.; Elimelech, M. The Global Rise of Zero Liquid Discharge for Wastewater Management: Drivers, Technologies, and Future Directions. Environ. Sci. Technol. 2016, 50, 6846-6855.

(17) Durham, B.; Mierzelewski, M. Water reuse and zero liquid discharge: a sustainable water resource solution. Water Supply 2003, 3, 97-103.

(18) Vishnu, G.; Palanisamy, S.; Joseph, K. Assessment of fieldscale zero liquid discharge treatment systems for recovery of water and salt from textile effluents. J. Cleaner Prod. 2008, 16, 1081-1089.

(19) Cui, P. Z.; Qian, Y.; Yang, S. Y. New Water Treatment Index System toward Zero Liquid Discharge for Sustainable Coal Chemical Processes. ACS Sustainable Chem. Eng. 2018, 6, 1370-1378.

(20) Davenport, D. M.; Deshmukh, A.; Werber, J. R.; Elimelech, M. High-Pressure Reverse Osmosis for Energy-Efficient Hypersaline Brine Desalination: Current Status, Design Considerations, and Research Needs. Environ. Sci. Technol. Lett. 2018, 5, 467-475.

(21) Bond, R.; Veerapaneni, S. Zero Liquid Discharge for Inland Desalination; Awwa Research Foundation: Denver, CO, 2007.

(22) Aquatech ZLD plant reduces water demand on the Nile. Membr. Technol. 2017, 2017 2. DOI: 10.1016/S0958-2118(17) 30024-1.

(23) Morillo, J.; Usero, J.; Rosado, D.; El Bakouri, H.; Riaza, A.; Bernaola, F. J. Comparative study of brine management technologies for desalination plants. Desalination 2014, 336, 32-49.

(24) Mickley, M. Survey of High-recovery and Zero Liquid Discharge Technologies for Water Utilities; WateReuse Foundation, 2008.

(25) Boo, C.; Elimelech, M. Thermal Desalination Membranes: Carbon nanotubes keep up the heat. Nat. Nanotechnol. 2017, 12, 501-503.

(26) Ettouney, H. Design of single-effect mechanical vapor compression. Desalination 2006, 190, 1-15.

(27) Apelblat, A.; Korin, E. The vapour pressures of saturated aqueous solutions of sodium chloride, sodium bromide, sodium nitrate, sodium nitrite, potassium iodate, and rubidium chloride at temperatures from $227 \mathrm{~K}$ to $323 \mathrm{~K}$. J. Chem. Thermodyn. 1998, 30, $59-71$.

(28) Brogioli, D.; La Mantia, F.; Yip, N. Y. Thermodynamic analysis and energy efficiency of thermal desalination processes. Desalination 2018, 428, 29-39.

(29) Lienhard, J. H.; Mistry, K. H.; Sharqawy, M. H.; Thiel, G. P. Thermodynamics, Exergy, and Energy Efficiency in Desalination Systems. In Desalination Sustainability: A Technical, Socioeconomic, and Environmental Approach; Arafat, H. A., Ed.; Elsevier Publishing Co., 2017; Chapter 4.

(30) Boo, C.; Winton, R. K.; Conway, K. M.; Yip, N. Y. Membraneless and Non-Evaporative Desalination of Hypersaline Brines by Temperature Swing Solvent Extraction. Environ. Sci. Technol. Lett. 2019, 6, 359-364.

(31) Davison, R. R.; Smith, W. H.; Hood, D. W. Phase Equilibria of Desalination Solvents - Water-Nacl-Amines. J. Chem. Eng. Data 1966, 11, 304-309.

(32) Hood, D. W.; Davison, R. R. The Place of Solvent Extraction in Saline Water Conversion. In Saline Water Conversion; American Chemical Society, 1960; Vol. 27, pp 40-49. 
(33) Bajpayee, A. Directional Solvent Extraction Desalination. Ph.D. Thesis, Massachusetts Institute of Technology, 2012.

(34) Bajpayee, A.; Luo, T.; Muto, A.; Chen, G. Very low temperature membrane-free desalination by directional solvent extraction. Energy Environ. Sci. 2011, 4, 1672-1675.

(35) Chen, X.; Yip, N. Y. Unlocking High-Salinity Desalination with Cascading Osmotically Mediated Reverse Osmosis: Energy and Operating Pressure Analysis. Environ. Sci. Technol. 2018, 52, 22422250.

(36) Chen, X.; Boo, C.; Yip, N. Y. Transport and structural properties of osmotic membranes in high-salinity desalination using cascading osmotically mediated reverse osmosis. Desalination 2020, 479, No. 114335.

(37) ASTM D5907-18. Standard Test Methods for Filterable Matter (Total Dissolved Solids) and Nonfilterable Matter (Total Suspended Solids) in Water; ASTM International: West Conshohocken, PA, 2018; www.astm.org.

(38) Koren, A.; Nadav, N. Mechanical vapour compression to treat oil field produced water. Desalination 1994, 98, 41-48.

(39) Zimerman, Z. Development of large capacity high efficiency mechanical vapor compression (MVC) units. Desalination 1994, 96, 51-58.

(40) Bell, L. E. Cooling, Heating, Generating Power, and Recovering Waste Heat with Thermoelectric Systems. Science 2008, 321, 1457.

(41) Kalogirou, S. A. Solar thermal collectors and applications. Prog. Energy Combust. Sci. 2004, 30, 231-295. 